\title{
Chapter 5 \\ EU and Member States Agreements with the Tobacco Industry
}

Preventive policies against illicit trade include cooperation frameworks established by the EU and the Member States with tobacco manufacturers. Over the years, collaboration with tobacco companies has taken place under two main formats: (i) voluntary, non-binding memoranda of understanding (MoU) signed by Member States individually and tobacco manufacturers, and (ii) legally binding enforceable agreements concluded between the EU (and its Member States) and the four largest tobacco manufacturers. The fate of these agreements will impact the control of tobacco illicit trade in both the UK and EU more widely. This will depend of their questionable renewal generally and application by the UK post Brexit.

\subsection{Voluntary Memoranda of Understanding}

International tobacco companies and some EU countries entered into voluntary partnerships in the form of memoranda of understanding (MoUs). The declared objective of MoUs is to combat illicit tobacco trade. The MoU between Philip Morris International (PMI) and Italy concluded in 1999 was among the first such instrument which served as a basis for dozens of similar agreements. The exact number of MoUs signed between international tobacco companies and government agencies is unknown, and generally the text of such agreements are not publicly available. Recent estimates put the figure at around 120 (20 signed by British American Tobacco (BAT), 24 by Imperial, 30 by Japan Tobacco International (JTI), and 50 by PMI). ${ }^{1}$

\footnotetext{
${ }^{1}$ Crosbie et al. (2019) Memoranda of understanding: a tobacco industry strategy to undermine illicit tobacco trade policies. 
In the specific case of the UK, the first MoU was signed in 2002 by Gallaher (later purchased by JTI) with HMC\&E (today HMCR). ${ }^{2}$ The general focus of the MoU, which is publicly accessible, is on cooperation and data sharing with the objective of limiting trade in smuggled and counterfeit goods. Although not binding, the MoU contains specific obligations. For instance, Gallaher undertakes to only supply products where there is a legitimate demand for the product in the intended final markets and where information indicates any substantial smuggling of its products, to take action to identify the supply routes and suspected export trade. Under the MoU, the company also has to refuse sales where the end-sale (consumption) destination is in doubt, revisit and where necessary discontinue the relationship with any particular distributor if it discovers improper behaviour. It has to immediately terminate the trading relationship if it concludes that any distributor is a smuggler of Gallaher products or that the distributor is knowingly or recklessly supplying a smuggler with such products. Also, pursuant to the MoU, Gallaher provides Customs, upon request, with all relevant information about the intended destination of export consignments as well as prompt access to export sales data.

Between 2002 and 2003, the UK Government signed similar MoUs with BAT, JTI and in Imperial Tobacco (now Imperial Brands plc). Like the MoU with Gallaher, the other MoUs focus on cooperation and information sharing, with a view of minimising the presence of the company's brands in the UK illicit market. None of these instruments creates binding legal obligations or foresees enforcement mechanisms.

The MoUs have attracted criticism. ${ }^{3}$ Some commentators have expressed concerns with regard to the non-transparent character of such instruments-thus potentially contravening FCTC Article 5.3 and the ITP. More generally, some have argued that international tobacco companies have promoted the conclusion of MoUs as a way to create connections with governments mainly to pre-empt more stringent regulation of illicit trade. Also, some have remarked that since MoUs are, by definition, not binding, they do not create accountability system or penalties for non-compliance, rendering them ineffective at controlling illicit trade. ${ }^{4}$

The MoUs signed by the UK and currently in force should remain unaffected by Brexit, irrespective of the modalities of the UK's withdrawal from the EU. The MoUs have been concluded by the UK Government/HMRC and neither the EU nor any EU institution or agency is a party to them. Also, contrary to the binding agreements discussed below, since the MoUs are not legally binding, the UK can unilaterally withdraw from them at any time.

\footnotetext{
${ }^{2}$ The text of the MoU is contained in a memorandum submitted by Gallaher Group Plc as written evidence ordered by the House of Commons in 2005. See UK Parliament (2005) Memorandum submitted by Gallaher Group Plc.

${ }^{3}$ Crosbie et al. (2019).

${ }^{4}$ Ibid.
} 


\subsection{Binding Agreements}

The MoUs described above should not be confounded with the legally binding and enforceable agreements concluded between the EU and the Member States, including the UK, on the one hand, and the world's four largest tobacco manufacturers on the other hand. In total, the EU and the Member States have signed four such agreements, three of which are still in force. The first one was signed in 2004 with PMI-the 'Anti-Contraband and Anti-Counterfeit Agreement and General Release'. It expired in 2016 without being renewed. The agreements with JTI are supposed to remain in place until 2022, whereas those with BAT and Imperial Tobacco are due to end in 2030. The texts of the agreements are available on the OLAF website. ${ }^{5}$

Under the terms of the four agreements, tobacco manufacturers agreed to pay a collective total of $\$ 2.15$ billion to the EU and to the Member States countries participating in the agreements with the objective of fighting cigarette smuggling and counterfeiting. The agreements also create obligations for tobacco manufacturers to prevent their products from falling into the hands of criminals, notably by supplying only those quantities required by the legitimate market, taking care that they sell to legitimate clients only ('know your customer' programs). They also have to implement a tracking system to help law enforcement authorities if cigarettes are traded illegally. Further, the agreements provide that companies shall compensate the European Commission and the Member States for lost taxes, duties, and other costs if the authorities seize illicit tobacco products that are not counterfeit and provide funding for anti-smuggling and anti-counterfeiting initiatives.

For instance, in the 2006-2015 period PMI paid a total of $€ 2,275,471.07$ for seizures in relation to the UK. Of this total figure, $€ 2,173,456.89$ went to the UK, whereas the remaining balance of $€ 102,014.18$ went to the EU. During the same period, the grand total (EU-wide) paid by PMI for seizures under the agreement amounted to $€ 68,228,115.38$. $^{6}$

The agreements have drawn criticism from some authors since inception. ${ }^{7}$ Indeed, some agreements were negotiated to settle or avoid legal disputes between tobacco manufacturers and the EU in relation to the involvement of the former in smuggling and money laundering. Regarding their usefulness in the fight against the evolving illicit trade in tobacco products, in 2016, the EU Commission published an assessment of the agreement with PMI. ${ }^{8}$ Although specific to the agreement with PMI, by and large the same findings apply to the other agreements as well. The EU Commission's assessment found that the PMI Agreement made an important contribution to fighting PMI illicit trade in the past. At the same time, it acknowledged how the

\footnotetext{
${ }^{5}$ See OLAF (2018) Tobacco Smuggling. Sweden did not sign the BAT and ITL agreements.

${ }^{6}$ Member States received $90.3 \%$ of payments whereas $9.7 \%$ went to the general EU budget. See European Commission (2016) Technical assessment of PMI Agreement and General Release, Annex 1-PMI Seizures Payments EU and Member State Shares.

${ }^{7}$ Joossens et al. (2016) Assessment of the European Union's illicit trade agreements with the four major Transnational Tobacco Companies.

${ }^{8}$ See European Commission (2016) Technical assessment of PMI Agreement and General Release.
} 
market and legislative framework have changed significantly since the entry into force of the Agreement.

The illicit market has undergone significant changes. Therefore, in its assessment, the EU Commission questioned the very relevance of such an instrument in light of the surge of cheap (illicit) 'whites', taking into account the administrative and reputational costs to public authorities resulting from the cooperation with tobacco manufacturers. ${ }^{9}$ The tobacco control and anti-illicit trade legislative setting has also evolved considerably since the entry into force of the PMI Agreement in 2004. The EU Commission's assessment highlights the limits of the PMI Agreement-and consequently of the other agreements as well-in effectively tackling today's illicit trade. In particular, TPD-2 introduces new tools in the fight against the illicit trade of tobacco products, as described in Sect. 6.1 below. The EU Commission's assessment nevertheless acknowledges that the PMI Agreement offers a global geographic scope concerning tracking at a master case level, but has only achieved partial global coverage in terms of marking at the pack level. ${ }^{10}$ Finally, the assessment finds that other important aspects regulated in the PMI Agreement, such as due diligence, anti-money laundering, seizure payments, and supports investigators, will be largely covered by new future rules under the FCTC Protocol.

To date, three agreements signed by the EU and the Member States, including the UK, remain in force. The JTI Agreement, ${ }^{11}$ together with the Mutual Cessation Agreement and the Agreement regarding Gallaher, was made on 14 December 2007 and binds JT International SA, JT International Holding BV, the EC, and the EU Member States. ${ }^{12}$ For the EC, the MoU was signed by the Commission (double signature Director General of the legal service and the Director General of OLAF). The JTI Agreement will expire on 14 December 2022. The BAT Agreement, ${ }^{13}$ made on 15 July 2010, binds British-American Tobacco (Holdings) Ltd, the EU, and 24 Member States. It will remain in force until 15 July 2030. The ITL Agreement,${ }^{14}$ made on 27 September 2010, binds Imperial Tobacco Ltd, the EU, and certain Member States. It should remain in force until 27 September 2030. In light of the outcome of the assessment of the agreement with PMI, it appears likely that the Commission will take the same view in respect of the other three Agreements currently in force.

\footnotetext{
${ }^{9}$ Ibid p. 29.

${ }^{10}$ Ibid p. 30.

${ }^{11}$ The agreement is available online at OLAF (2016) Japan Tobacco 2007.

${ }^{12}$ The agreements were all executed on 14 December 2007. 26 Member States signed the agreements on the execution date; the UK signed the agreements in April 2009. The EU took over the legal obligations of the EC in December 2009.

${ }^{13}$ The agreement is available at OLAF (2016) British American Tobacco (BAT) 2010.

${ }^{14}$ The agreement is available at OLAF (2016) Imperial Tobacco Limited (ITL) 2010.
} 
The three EU binding agreements with the manufacturers will stop applying with regard to the UK after Brexit day. Should the UK nevertheless consider maintaining such instruments, parties could negotiate a 'roll over'. The UK could thus become a stand-alone party in subsequent agreements with large tobacco manufacturers that mirror the content of the original ones. The UK has already negotiated the 'roll over' of several free trade agreements it has subscribed to as an EU Member, as discussed in Section 4 above. However, if the UK will consider the conclusions reached by the EU Commission on this topic, the request for post-Brexit industry agreements may have to come from the industry itself proving their continued relevance. As pointed out in the Commission's assessment, ITP has a global reach and "contains many provisions broadly similar to those of the tobacco agreements". ${ }^{15}$ Beside the questions relating to the actual need for such formal cooperation, any involvement of the industry risks facing considerable challenges by various stakeholder groups, including under Art. 5.3 of the FCTC requiring protection of tobacco control policies from commercial and other vested interests of the tobacco industry. ${ }^{16}$

\section{References}

Crosbie E, Bialous S, and Glantz SA (2019) Memoranda of understanding: a tobacco industry strategy to undermine illicit tobacco trade policies. In: BMJ Journals, Tobacco Control, Published Online First: 18 Jan 2019. https://tobaccocontrol.bmj.com/content/tobaccocontrol/early/2019/01/ 18/tobaccocontrol-2018-054668.full.pdf?ijkey=rF5sMQ7tKIfiniE\&keytype=ref. Accessed 24 Feb 2020

European Commission (2016) Technical assessment of the experience made with the anticontraband and anti-counterfeit agreement and general release of 9 July 2004 among Philip Morris International and affiliates, the Union and its Member States. European Commission Staff Working Paper, Brussels, 24 Feb 2016, SWD (2016) 44 final. https://ec.europa.eu/anti-fraud/ sites/antifraud/files/technical_assessment_pmi_24022016_en.pdf. Accessed 24 Feb 2020

Joossens L, Gilmore AB, Stoklosa M, and Ross H (2016) Assessment of the European Union's illicit trade agreements with the four major transnational Tobacco companies. In: BMJ Journals Tobacco Control vol 25(3), pp 255-260. https://tobaccocontrol.bmj.com/content/25/3/254. Accessed 24 Feb 2020

OLAF (2016) British American Tobacco (BAT) 2010. European Anti-Fraud Office. https://ec. europa.eu/anti-fraud/investigations/eu-revenue/bat_en. Accessed 24 Feb 2020

OLAF (2016) Imperial Tobacco Limited (ITL) 2010. European Anti-Fraud Office. https://ec.europa. eu/anti-fraud/investigations/eu-revenue/imperial_tobacco_en. Accessed 24 Feb 2020

OLAF (2016) Japan tobacco 2007. European Anti-Fraud Office. https://ec.europa.eu/anti-fraud/ investigations/eu-revenue/japan_tobacco_2007_en. Accessed 24 Feb 2020

OLAF (2018) Tobacco smuggling. European Anti-Fraud Office. https://ec.europa.eu/anti-fraud/ investigations/eu-revenue/cigarette_smuggling_en. Accessed 24 Feb 2020

\footnotetext{
${ }^{15}$ European Commission (2016) Technical assessment of PMI Agreement and General Release, p. 7.

${ }^{16}$ Art. 5.3 of the FCTC reads "In setting and implementing their public health policies with respect to tobacco control, Parties shall act to protect these policies from commercial and other vested interests of the tobacco industry in accordance with national law.".
} 
UK Parliament (2005) Memorandum submitted by Gallaher Group Plc. Select committee on treasury written evidence. https://publications.parliament.uk/pa/cm200405/cmselect/cmtreasy/126/ 126we20.htm. Accessed 24 Feb 2020

Open Access This chapter is licensed under the terms of the Creative Commons Attribution 4.0 International License (http://creativecommons.org/licenses/by/4.0/), which permits use, sharing, adaptation, distribution and reproduction in any medium or format, as long as you give appropriate credit to the original author(s) and the source, provide a link to the Creative Commons license and indicate if changes were made.

The images or other third party material in this chapter are included in the chapter's Creative Commons license, unless indicated otherwise in a credit line to the material. If material is not included in the chapter's Creative Commons license and your intended use is not permitted by statutory regulation or exceeds the permitted use, you will need to obtain permission directly from the copyright holder.

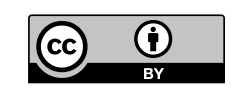

